\title{
Intergenerational Social Mobility and Self-Rated Health in Europe*
}

\author{
Patrick Präg and Alexi Gugushvili
}

August 2020

\begin{abstract}
Occupational class and health are closely linked, however the health consequences of intergenerational social class mobility have not yet been systematically explored. A long tradition of research on individuals' class mobility and health reports mixed or no effects, however crossnational differences have rarely been tested comprehensively. Further, recent studies show that intergenerational social class mobility at the societal level is beneficial for population health. Using representative survey data from 30 European countries $(N=159,591)$, we present the first study to investigate the role that intergenerational class mobility both at the individual and societal level play for self-rated health. We find that, apart from four post-communist countries, neither downward nor upward mobility is significantly and systematically related to poor self-rated health. There is also no association between societal-level social mobility and the prevalence of poor self-rated health across the 30 societies. Results are robust to alternative specifications and suggest that individuals' own social class and partially their parents' social
\end{abstract}

*Data used in this study are publicly available (ESS 2002, 2004, 2006, 2008, 2010), a replication package with Stata do-files for all analyses shown is available on-line (Präg and Gugushvili 2020). 
class are primary explanations of health rather than their mobility experiences between origins and destinations.

\section{Introduction}

In times of declining and stagnating social mobility in developed countries (Breen and Müller 2020; Grätz et al. 2019; Narayan et al. 2018), understanding the health consequences of this process for individuals and societies is key for maintaining and improving population health. Social scientists and public health researchers have long been examining the wellbeing consequences of social mobility (e.g. Bartley and Plewis 1997; Campos-Matos and Kawachi 2015; Schuck and Steiber 2018; Sorokin 1927; Steiber 2019; Vable, Gilsanz, and Kawachi 2019), often leading to null or contradictory findings. One of the reasons why there is little consensus is that only few studies have systematically examined how countries differ in their social mobility effects on health. Some studies - drawing on small numbers of countries - suggest that there might be important country differences (Gugushvili et al. 2019; Hadjar and Samuel 2015).

In addition to the role of cross-national socio-demographic and socio-economic differences, government action could modify the micro-mechanisms linking social mobility to health through various policies such as early childhood interventions, improving quality of schooling, smoothing school-to-work transitions, or improving working lives (Mackenbach 2019). Welfare state interventions can improve the living conditions of the most disadvantaged groups and can ameliorate harmful exposures which are linked to socio-economic disadvantages via, for instance, unemployment insurance. Even if individuals through their social mobility trajectories become more vulnerable to developing ill-health, access to good-quality health care can mitigate the links between mobility and health. Policies can also affect the consequences of social mobility through legislative protection of sick workers from discrimination (Campos-Matos and Kawachi 2015). 
Further, recent ecological studies suggest that there might be health consequences to societal- or regional-level social mobility (Gugushvili and Kaiser 2020; Venkataramani, Daza, and Emanuel 2020). Spatial and demographic groups which are characterized by having high social fluidity have better health outcomes. Being based on ecological data only, however, these studies cannot account for individual-level social mobility experiences and are marred by the well-known ecological fallacy of population-level associations between health and other macro-level characteristics (Subramanian et al. 2009). They also do not differentiate between specific effects stemming of downward vs. upward mobility. This is important because moving downwards in social hierarchy can have different effect from moving upwards.

This study is the first to analyze intergenerational social mobility and its associations with self-rated health both at the individual as well as the societal level across a large number of countries. Drawing on representative survey data from 30 European countries and more than 150,000 participants, this study addresses four research questions:

1) Is the social mobility experience of individuals associated with self-rated health?

2) Is there variation in the association between individuals' social mobility and self-rated health across European societies?

3) Is social mobility in a society associated with average self-rated health in a society?

4) Does social mobility in a society affect the association between individuals' social mobility and self-rated health across European societies?

Different pathways can potentially link individuals' mobility to their health. In basic terms, social mobility refers to a movement to a better or worse socio-economic environment than the one which individuals were born and grew up in. Yet, since there is overwhelming evidence that socio-economic conditions determine health (Marmot 2005), we are not interested per se in 
how attained socio-economic position as a result of social mobility affects health. We rather study the unanswered question if an intergenerational journey, net of origin and destination effects, is linked to better or worse health outcomes than those observed among individuals who remain in their origin class. Negative health consequences of upward social mobility have been one of the oldest sociological hypotheses, positing that individuals' mobility journey causes anxiety and maladjustment in a new socio-economic environment (Sorokin 1927). In recent decades, with growing economic stagnation and more individuals experiencing downward social mobility (Chetty et al. 2017), a new theoretical explanation of negative health outcomes of downward social mobility has emerged. The dominant perspective in this area posits that a loss of advantaged ascribed socio-economic position obtained at birth is a stressful life event and individuals find it difficult to adjust psychologically to new environments, leading to worse health and wellbeing outcomes (Newman 1999).

In addition to individual-level effects, mobility patterns of an entire society might also be linked to health outcomes. We suggest two theoretical mechanisms for this: First, social mobility is widely believed to be an indicator of equality of opportunity (Swift 2004), therefore individuals' worldviews on how fair and unequal the societies they live in are likely affected by higher or lower levels of social mobility. In turn, the perception of inequality, which is also driven by income inequality at a societal-level, is known to be a major predictor of worse health outcomes (Gugushvili, Reeves, and Jarosz 2020; Präg, Mills, and Wittek 2014). The second mechanism, based on the economic theory of health capital (Grossman 1972), assumes that individuals at the outset of their careers have an intrinsic motivation to realize their full potential in life, but this incentive is enhanced or suppressed depending on how mobile the societies they live in are. In more socially fluid environments, individuals from disadvantaged backgrounds are likely to increase health investments and lead healthier lives as they anticipate upward social mobility and the associated socio-economic benefits associated with this process (Venkataramani et al. 
2016).

Next to direct links between societal-level social mobility and population health, the strength of the association between one's mobility trajectory and one's health can be moderated by societal-level social mobility. As discussed above, individuals might be motivated to have healthy lives and in more socially fluid societies they might also be less stressed because of the greater equality of opportunity. However, the effect of individual-level experience of mobility on health might be differ according to the amount of social mobility in a society. On the one hand, in an environment where moving up and down in the social hierarchy is a relatively frequent occurrence, detrimental health effects as postulated by the dissociative thesis might not be as pronounced as in a society where social mobility is rare. On the other hand, if a society is intergenerationally static and downward mobility occurs only in exceptional circumstance, those who move down in social hierarchy, i.e. 'fall from grace' (Gugushvili, Zhao, and Bukodi 2019), might experience even more emotional anxiety with detrimental consequences for health than otherwise would happen if downward mobility was not an unusual life course event (Kaiser and Trinh 2019).

In sum, our study makes the following contributions. First, we analyze representative survey data from a large number of countries in Europe. Previous comparative studies have only considered handful of countries. A small sample of countries in previous research prevented testing the effect of societal-level mobility on health. Further, we consider both absolute and relative measures of contextual-level social mobility, which might have different effects on health. Lastly, we operationalize social mobility as mobility in occupational social class which is sociologists' preferred indicator of mobility as it is arguably better able to capture intergenerational transmission of (dis)advantages (Erikson and Goldthorpe 2002).

NAMES_STDNAMES_STDNAMES_STD 


\section{Data and methods}

Analyses are based on five rounds of the European Social Survey (2002-10), a large-scale, biennial nationally representative survey of the general population of over 30 European societies, which has become an established resource for public health research (Huijts et al. 2017). We restrict analyses to the first five rounds of the survey, as these are the only ones including detailed information on survey participants' parental occupation (Ganzeboom 2013). Further, we restrict our analyses to participants who were 30 years and older at the time of the data collection. The age limit ensures that participants have reached occupational maturity (Bukodi et al. 2015). We exclude participants for whom parental occupation or other variables are not observed, as well as country samples with lacking societal-level data ${ }^{1}$. Table A1 in the Supplement lists the 30 countries included in our analyses and shows sample sizes per survey round.

Our outcome variable is self-rated health, measured with the question 'How is your health in general?' and response options ranging from 'Very bad' to 'Very good.' We distinguish between poor ('Very bad' and 'Bad') self-rated health and the remaining categories. Self-rated health is seen as a general appraisal of one's health status, not connected to any specific illness, but covering mental, physical, and social aspects of health (Idler, Hudson, and Leventhal 1999). It has been shown to predict mortality and morbidity and has high test-retest reliability in a number of studies (Lorem et al. 2020) and is an oft-used measure in cross-national health research in the absence of physical examinations' data (e.g. Gugushvili, Jarosz, and McKee 2019; Präg and Subramanian 2017; Präg, Wittek, and Mills 2017). Research has also shown that the associations between objective health indicators and selfperceived health are largely similar across socioeconomic groups (McFadden et al. 2009), but some argued that cultural norms may be biasing comparisons across countries (Grol-Prokopczyk et al. 2015).

\footnotetext{
${ }^{1}$ Specifically, we exclude Croatia, Iceland, Israel, and Turkey.
} 
Intergenerational occupational class mobility is our main predictor variable. At the individual level, mobility is gauged by comparing participants' social class to the social class of their parents. Social class of both participants and their parents is measured in terms of the European Socio-Economic Classification (ESEC, Rose and Harrison 2010), distinguishing between three social class categories: 1) salariat, 2) intermediate classes, and 3) working class. Examples for a salariat, intermediate, and working class occupations are, respectively, lawyers or scientists, government social benefits officials or office clerks, and cleaners or drivers. Participants who were not in paid work or not on the labor market were assigned a class based on their last job. For gauging parental social class, we use the 'dominance approach' (Erikson 1984), i.e. the highest class position of either parent when the participant was 14 years of age. The individual-level measure of intergenerational social mobility has three categories. Participants with a higher social class position than their parents are considered upwardly mobile, participants with a lower class than their parents are downwardly mobile. Participants in the same class position as their parents are classified as immobile (or stable).

At the societal level, we distinguish between different forms of intergenerational mobility. Absolute mobility is concerned with the share of people in a society who are upwardly or downwardly mobile, i.e. the absolute difference between the current and previous generations. This is the type of mobility individuals are able to directly observe and experience in their everyday lives. Our main measure of absolute mobility is the ratio between absolute upward mobility, i.e. the population share that has moved upward from their parental origin class, and downward mobility, i.e. the population share that has moved downward from their origin. A higher ratio thus indicates greater absolute mobility in a country.

Relative mobility, often assumed by scholars as a more appropriate measure of how fair a society is, is the association between individuals' origin and destination positions net of all changes taking place in the class structure between the parental generation and the participants' generation. It is 
also referred to as social fluidity or equality of opportunity. We use the 'unidiff' parameter from the uniform difference model (Erikson and Goldthorpe 1992) as our measure of relative mobility. Higher values indicate a stronger association between parent's and children's social class and hence less relative mobility in a society. Data on absolute and relative mobility rates are taken from Bukodi, Paskov, and Nolan (2020), who provide further details on the aggregate mobility measures.

All measures of intergenerational mobility on the societal level refer to the mobility of men only. Men's mobility rates are a more consistent measure of opportunity structures in cross-national comparisons (Bukodi et al. 2020). Female mobility rates vary across countries due to national idiosyncracies like different levels of female labor market participation and part-time work (Beham et al. 2019; Beham, Präg, and Drobnič 2012).

Furthermore, as control variables we use age and gender of participants and the round of data collection and country. Next to individual-level controls, we account for GDP per capita as a proxy for the wealth of a country, which can be a confounder of the association between mobility and health (Yaish and Andersen 2012). We obtained GDP per capita from the World Development Indicators database (World Bank 2020) for the years 2002-10 and calculated the average GDP per capita based on purchasing power parity for each country over this eight-year period. We further log GDP per capita to pull in outliers. Country-level variables are shown in Table A3 in the Supplement, and Table A4 shows their intercorrelations.

\section{Analytical strategy}

Our analysis proceeds in four steps, corresponding to our four research questions.

Diagonal reference models. To answer the first research question, we investigate the role of origin and destination class for self-rated health and examine 
the association between individual social mobility and self-rated health. For these analyses, we make use of diagonal reference models (DRM, Van der Waal, Daenekindt, and Koster 2017), a statistical approach for disentangling the effects of origin class, destination class, and mobility trajectory in an upward or downward direction. Social mobility effects are the difference between social class origin and class destination and therefore conventional regression models cannot identify social mobility effects due to collinearity. Instead, diagonal reference models use the socially immobile as a reference group against which the socially mobile are compared to. Specifically, diagonal reference models estimate the effects of origin and destination class on the outcome using a single vector of coefficients for both class positions along with weighting parameters, which represent the relative importance of the origin and destination classes:

$$
Y=a+p * \mu_{i i}+q * \mu_{j j}+b \mathbf{X}
$$

$a$ is the model intercept. Subscripts $i$ and $j$ represent the social position of origin and destination, respectively. $\mu_{i i}$ and $\mu_{j j}$ are both estimates of $Y$ in the main diagonal. $p$ represents the relative importance of the class of origin, and $q$ the relative importance of the destination class (and $p=1-q$ ). $\mathbf{X}$ is a vector of covariates that can be interpreted like regression coefficients. We use a logit link function for the model, as our outcome poor self-rated health is a binary variable.

To estimate the mobility effects, we extend the model with mob, a vector of dummy variables indicating the mobility trajectory of respondents:

$$
Y=a+p * \mu_{i i}+q * \mu_{j j}+b \mathbf{X}+c \mathbf{m o b}
$$

To estimate our diagonal reference models, we make use of the 'drm' (Kaiser 2019) command for Stata. 
For the second research question, we repeat analyses from the first step for each country separately. We examine the origin weight and the coefficients of the mob dummy variables along with their 95 per cent confidence intervals, which allows us to investigate any cross-country heterogeneity.

Two-step multilevel analyses. To answer the third research question, we examine the context effects of country-level mobility indicators. For this, we conduct two-step multilevel analyses as suggested by Mills and Präg (2016). First, we estimate the prevalence of poor self-rated health in a country accounting for compositional differences between countries via country-specific logit regressions, i.e. we account for own and parental social class, age, sex, and survey round:

$$
\log \frac{p}{1-p}=b_{0}+b_{1} \text { class }+b_{2} \text { parentalclass }+c \text { controls }
$$

We use these country-specific equations to obtain predicted probabilities of poor self-rated health per country. These can be interpreted as the hypothetical prevalence of poor health in a country if the class and demographic composition was the same in all countries. In a second step, we correlated these adjusted prevalences of self-rated health with country-level mobility indicators with bivariate scatterplots. In a third step, we estimated these associations with random effects meta-analysis (Harbord and Higgins 2008), which take the uncertainty around the predicted prevalences of self-rated health into account and allow us to take the additional country-level control variable logged GDP per capita into account. A sample size of 30 restricts the number of control variables that can be accounted in a regression model, but GDP per capita is a key indicator of national wealth and potentially an important confounder of the social mobility-health association and hence a crucial robustness check.

Cross-level interactions in two-step multilevel analyses. For the fourth research question, we draw on the country-specific mobility effects estimated to answer 
the second research question and correlate these with country-level mobility indicators with bivariate scatterplots. In a further step, we replicate these associations in random effects meta-analyses and further account for logged GDP per capita.

Robustness checks. To assess the robustness of our findings, we conduct various checks. First, we replicate our country-level findings with alternative indicators of social mobility. For absolute social mobility, we use the percentages of upwardly and downwardly mobile individuals separately. For relative social mobility, we make use of the global log odds ratios. All indicators are taken from Bukodi et al. (2020). We replicate the descriptive scatterplot analyses as well as the random-effects meta-regressions with these alternative indicators. Second, we stratify models by sex to examine any gender-specific effects in the social mobility-health association. Third, we restrict the sample to participants up to a) 60 years and b) 70 years old to ensure that a) respondents are still on the labor market and occupational class is still a salient category for their health and that b) findings are not sensitive to between-country differences in life expectancy. Finally, we add education as a control variable. Education is an important pathway variable in the social mobility process, and therefore should not be included in models aiming to gauge the health consequences of social mobility, as controlling for pathway variables biases the parameters of interest. Nonetheless, our results do not change when adding education to the model.

Replicability. Data used in this study are publicly available (ESS 2002, 2004, 2006, 2008, 2010), a replication package with Stata do-files for all analyses shown is available on-line (Präg and Gugushvili 2020). 


\section{Results}

\section{Descriptive statistics}

Figure 1 shows the percentage of participants with poor self-rated health by social class origin and destination. The main diagonal of the Figure shows the class gradient in poor health for the socially immobile. To the right of the main diagonal are the upwardly mobile, and below the diagonal are the downwardly mobile. The downwardly mobile have higher prevalences of poor self-rated health than the upwardly mobile, but this could be simply because the upwardly mobile groups do not include those who ended up in the working class, while downwardly mobile groups do not include those who ended up in the salariat class. While illuminating, the descriptive statistics are not enough to warrant conclusions about social mobility effects per se.

\section{Is the social mobility experience of individuals associ- ated with self-rated health?}

[Table 1: Poor self-rated health regressed on social class and social mobility, diagonal reference model, log odds coefficients (95\% confidence intervals based on cluster-robust standard errors in parentheses)]

Table 1 reports results from two diagonal reference models estimated for the pooled sample. The coefficients from a diagonal reference model can be interpreted as follows: The coefficients in the immobiles section refer to those participants who remained in their social class of origin and the log odds of poor health among those follow the well-known social class gradient in health. Log odds of poor health for the salariat are much smaller than for the other classes and much higher for those from the working class. The origin weight usually ranges between zero and one and denotes the importance of the origin for the outcome - in Model (1), the origin weight is .24, indicating that class destination exerts a much bigger influence on self-rated health than social origin. 


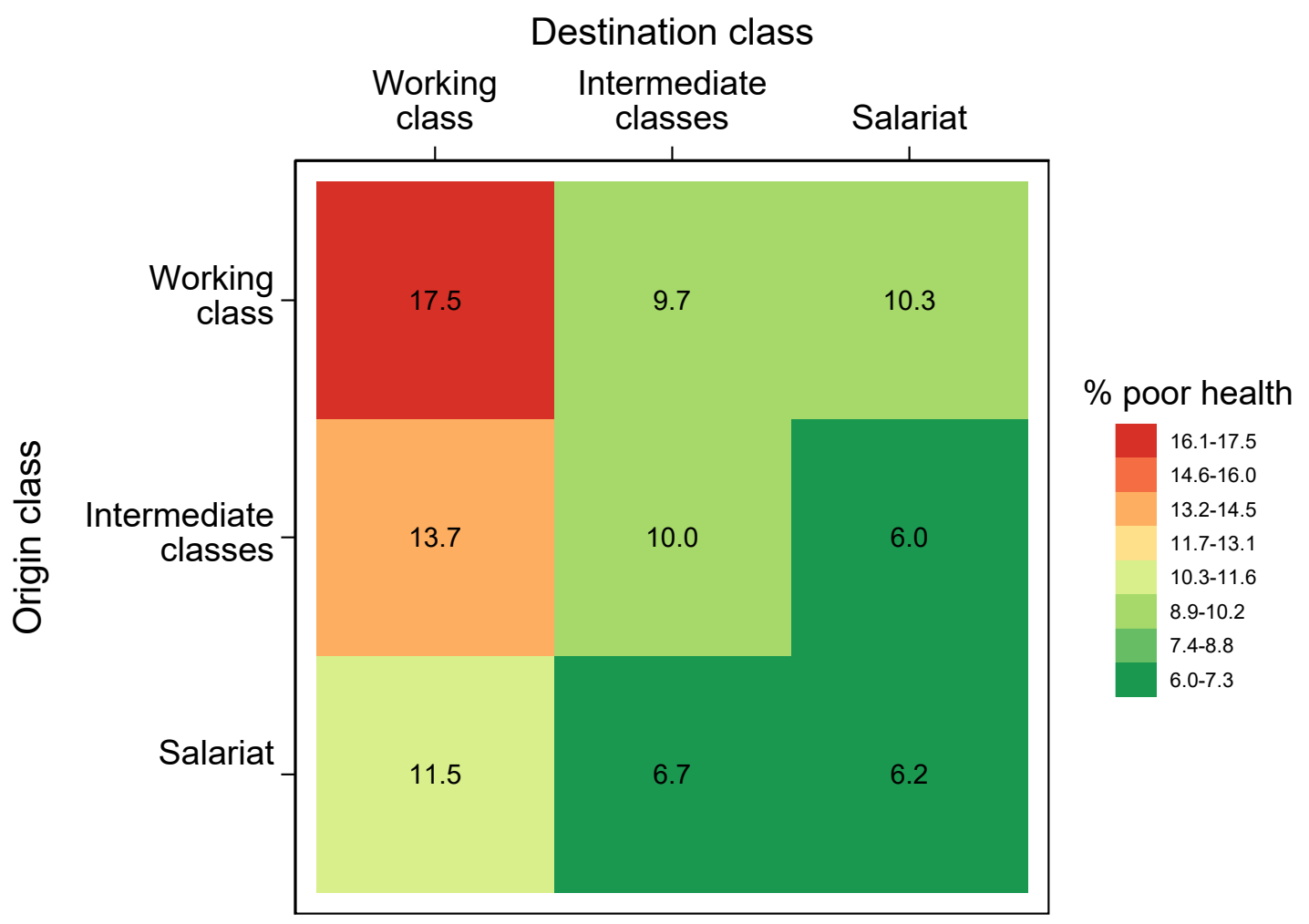

Figure 1: Average Self-rated health in Europe by social class of origin and destination. Notes: Percentages weighted by population size and post-stratification weight. See Präg (2019) for visualization details. 
Table 1: Poor self-rated health regressed on social class and social mobility, diagonal reference model, odds ratios (95\% confidence intervals based on cluster-robust standard errors in parentheses)

(1)

\begin{tabular}{lcc}
\hline Immobiles & & \\
Salariat & $0.67^{* * *}$ & $0.67^{* * *}$ \\
Intermediate & {$[0.62,0.72]$} & {$[0.62,0.72]$} \\
& $0.93^{*}$ & 0.94 \\
Working & {$[0.87,0.99]$} & {$[0.86,1.03]$} \\
& $1.61^{* * *}$ & $1.59^{* * *}$ \\
& {$[1.54,1.69]$} & {$[1.51,1.67]$} \\
\hline Weight parameter & & \\
Origin weight & 0.24 & 0.32 \\
& {$[0.20,0.28]$} & {$[0.15,0.49]$} \\
\hline Covariates & & \\
Age (centered) & $1.06^{* * *}$ & $1.06^{* * *}$ \\
& {$[1.05,1.06]$} & {$[1.05,1.06]$} \\
Female (ref. male) & $1.28^{* * *}$ & $1.28^{* * *}$ \\
& {$[1.15,1.43]$} & {$[1.15,1.43]$} \\
Mobility parameters (ref. stable) & & 1.03 \\
Downwardly mobile & & {$[0.94,1.12]$} \\
& & 0.91 \\
Upwardly mobile & & {$[0.79,1.05]$} \\
& $-3.32^{* * *}$ \\
Constant & $-3.34^{* * *}$ & {$[-3.44,-3.20]$} \\
Country dummies included & Yes & Yes \\
Survey round dummies included & Yes & Yes \\
\hline Observations & 159,591 & 159,591 \\
AIC & 89677.3 & 89676.8 \\
BIC & 89767.1 & \\
\hline & & 89786.6 \\
\hline
\end{tabular}

${ }^{*} \mathrm{p}<.05,{ }^{* *} \mathrm{p}<.01,{ }^{* * *} \mathrm{p}<.001$.

Destination parameters (which equal $-1 *$ origin parameters) and destination weight (which equals 1 - origin weight) not displayed. 
Model (2) of Table 1 examines whether social mobility is affecting poor selfrated health. Indeed, the model shows that neither upward nor downward mobility are associated with poor health in the pooled sample of 30 European countries. Yet, the introduction of social mobility parameters increased the origin weight by about a third to 0.32 , suggesting that the destination has a weaker effect on self-rated health when social mobility is accounted for in the model.

\section{Is there variation in the association between individuals' social mobility and self-rated health across European societies?}

But is there cross-national variation in the role of social origin and social mobility for health? This is a relevant question because it is possible that in the analysis of the pooled sample significant effects in some countries are cancelled out by insignificant effects in other countries. To answer this question, Figure 2 shows the origin weights from country-specific diagonal reference models in Panel A. In all countries the origin weight is below 0.5, suggesting that individuals own social class is more important for health than parental social class. Nonetheless, in many countries origin class still plays an important role, as the confidence interval is not different from 0.5 , indicating that the role of origin is just as big as destination.

In Panel B of Figure 2, we observe how downward mobility is related to poor self-rated health in European societies. In 28 out of 30 countries, the confidence intervals of the point estimates cross the 0-reference line. In Slovenia and Ukraine, the downwardly mobile have a higher likelihood of reporting poor self-rated health. For the links between upward mobility and health, no consistent and systemic associations are observed.

In Panel C of Figure 2, for roughly equal numbers of countries point estimates lie above and below the 0-reference line, but these estimates are not statistically 
significant apart for Ukraine, Poland, Slovakia, and Slovenia. The main characteristic which unites the countries where significant effects are observed is that all of them are former communist societies.

\section{Is social mobility in a society associated with average self-rated health in a society?}

Panels A1 and A2 of Figure 3 show the associations between absolute and relative social mobility and the prevalence of poor self-rated health in a country. There is an association between absolute social mobility and health. The more upward mobility in a society, the lower the prevalence of poor health. The strength of the association is however modest $(\mathrm{R}$-squared $=.25$ ), and as will be seen in the robustness checks (Table A5 in the Supplement), disappears when GDP per capita is being controlled for, suggesting that the higher levels of absolute upward mobility are an indicator of economic upgrading, which in turn is a significant predictor of health. The association between relative social mobility, i.e. equality of opportunity, and self-rated health, is negligible.

\section{Does social mobility in a society affect the association between individuals' social mobility and self-rated health across European societies?}

The middle and bottom rows of Figure 3 show the associations between individual upward (B Panels) and downward effects (C Panels) on self-rated health and absolute and relative mobility in a society. For none of the combinations of variables, significant associations can be found, suggesting that the individual mobility effects on health operate independently of the societal mobility context in a society. 
A

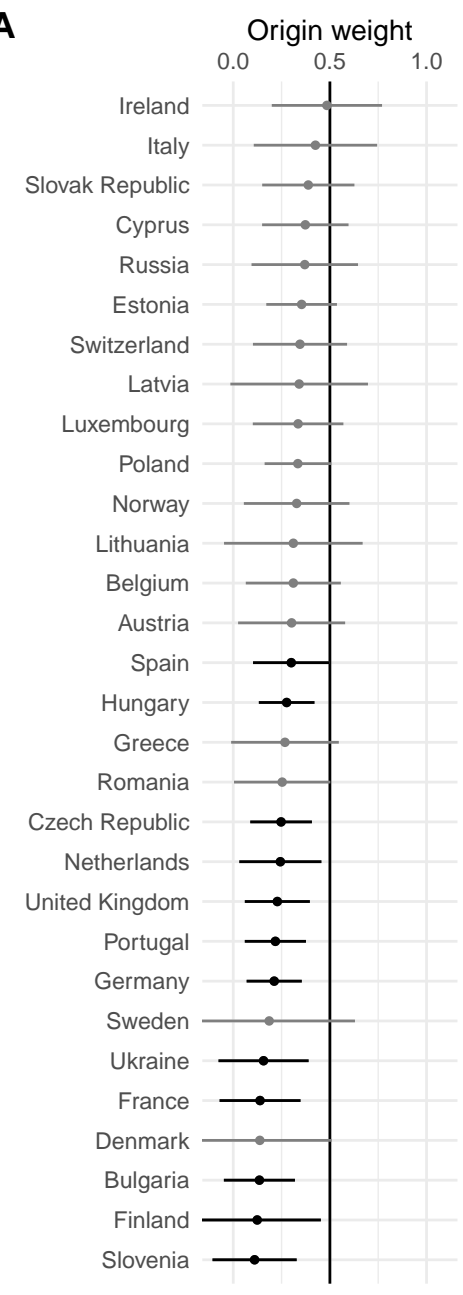

B

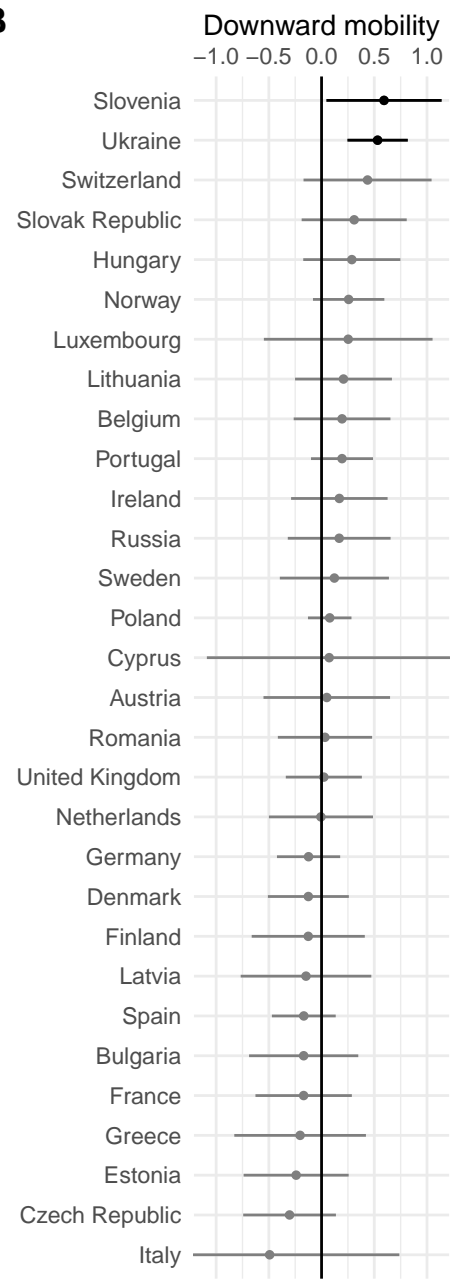

C
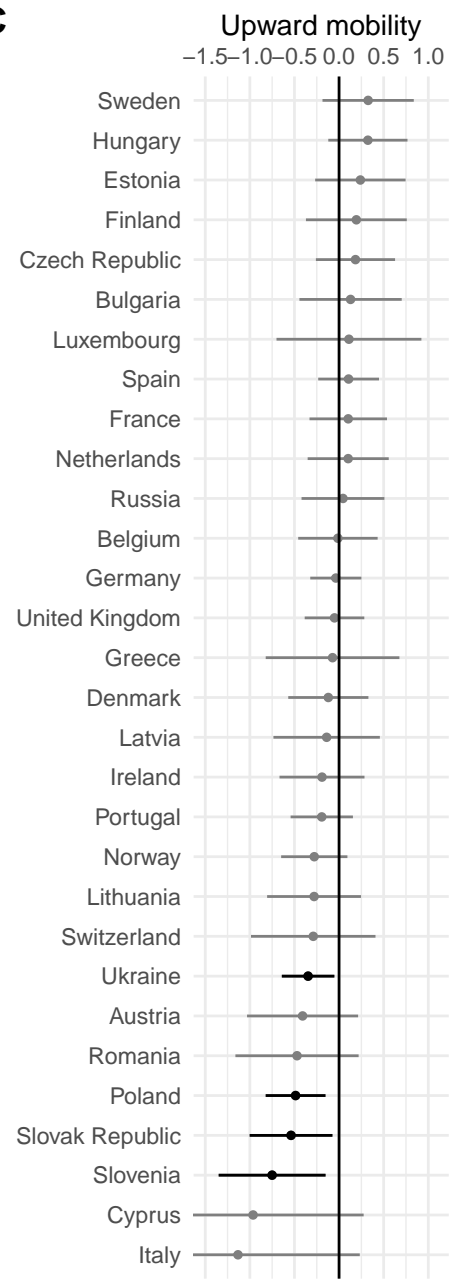

Figure 2: Figure 2, Panel A: Origin weights from country-specific diagonal reference models controlling for age and sex. Panels B and C: Downward and upward mobility parameters from country-specific diagonal reference models controlling for age and sex. Notes: 95\% confidence intervals not shown when below 0 or above 1 (Panel A), below -1 or above +1 (Panel B), or below -1.5 or above +1 (Panel $\mathrm{C}$ ). 

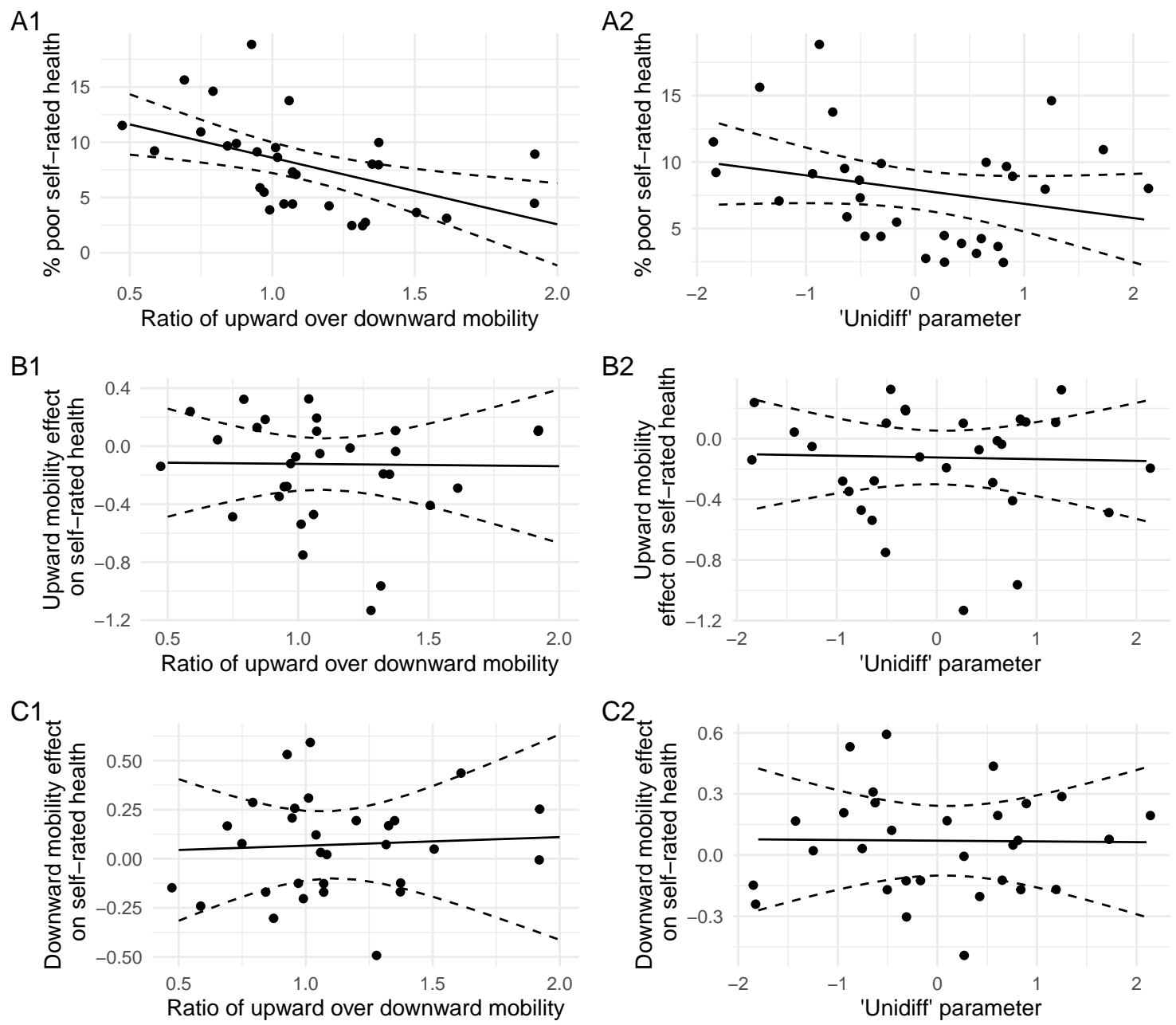

Figure 3: Figure 3, top row: Indicators of absolute (Panel A1) and relative social mobility (Panel A2) plotted against predicted percentage poor health in country. Middle row: Indicators of absolute (Panel B1) and relative social mobility (Panel B2) plotted against upward mobility effect on poor health in country. Bottom row: Indicators of absolute (Panel C1) and relative social mobility (Panel C2) plotted against downward mobility effect on poor health in country. Notes: Regression lines are based on random effects meta-regressions with $95 \%$ confidence intervals, all analyses $N=30$. 


\section{Robustness checks}

We conduct a number of robustness checks that are fully documented in the Supplement. First, we use alternative indicators of social mobility for our country-level analyses, shown in Figure A1. Results are in line with those seen in Figure 3. Second, we run random-effects meta-regressions for our country-level analyses, which allow us to take the uncertainty around our individual-level estimates into account and which further allow us to take GDP per capita as a control variable into account. Results stay largely unaffected, only the associations between absolute mobility and health render insignificant once GDP is controlled for (Table A5). Third, we stratify analyses by sex (Table A6), revealing no gender differences. Fourth, we remove participants older than 60 years and 70 years from the sample, which does not further affect our findings (Tables A6 and A7). Finally, we control for education, which does not affect our results (Table A8).

\section{Discussion}

Social mobility is an important part of modern life, with accelerating technological progress resulting in a changing occupational structure and corresponding mobility of individuals from one generation to another. However, recent evidence on stagnating levels of absolute upward mobility in industrialized nations also suggests that an increasingly larger share of individuals struggles to achieve the same standard of living as their parents did, while many also experience downward intergenerational mobility. What are then implications of social mobility for individuals' health? That the changing position in the socio-economic hierarchy is related to different health outcomes is not surprising, but how the journey itself from one's origin to one's destination affects health remains largely unexplained. Although various theoretical approaches predict negative and positive effects, depending on the direction of social mobility, until recently mobility effects on health outcomes have not been studied with appropriate statistical tools across large numbers of societies. 
Using high-quality comparative data on individuals' social class mobility, their self-rated health and diagonal reference models to correctly pinpoint mobility effects, we did not find that either downward or upward mobility is significantly related to individuals' health. These finding hold with the analyses of the pooled sample of countries as well as in investigation of mobility effects separately in 30 countries. Analyses of the relative importance of parental and own social class also suggest that in most countries individuals' current social class position is more important than their childhood environment, but parental social class still explains some part of variation in self-rated health. Social mobility at the individual-level was related to health in four postcommunist countries: Poland, Slovakia, Slovenia, and Ukraine. It is difficult to say whether the post-communist experience is the main explanation of the observed association, as our analysis also included eight other post-communist countries in which no effects of mobility were revealed. However, we can say that post-communist societies are characterized by low upward and high downward mobility levels and much worse health outcomes than Western European societies (Mackenbach, Karanikolos, and McKee 2013). As for specific country characteristics, Slovenia and Slovakia are some of the most successful post-communist societies which experienced a smooth transition to a market-based economy and democratic political regimes. Poland and Ukraine are also neighboring countries with quite different transition experiences; the former managed to become the first post-communist country classified as a "developed market," while the latter experienced one of the most inefficient reforms and political turmoil.

Our analysis of contextual effects also did not reveal that societal-level social mobility has a significant association with mean self-rated health across countries or that it moderates the effect of individual-level mobility on selfrated health. One of the explanations of this negative finding is that people are not good at gauging social mobility at the macro-level (Alesina, Stantcheva, and Teso 2018; Chambers, Swan, and Heesacker 2015; Cheng and Wen 2019; Kraus and Tan 2015). If so, then individuals experiencing, for instance, 
downward mobility would not know how prevalent this experience is in their society and consequently they could not be affected by the theoretical mechanism described in the introduction.

One of the reasons why we do not observe mobility effects could be our operationalization of social mobility and relying on self-rated health as an outcome variable. Although the three-fold version of ESEC social class is a cross-nationally validated indicator of class stratification (Paskov, Präg, and Richards 2020), it also conceals significant variation within the class spectrum. Besides, unlike the studies on health effects of income mobility which usually consider mobility in relative income attainment, our social class mobility approach on an individual level does not explicitly account for intergenerational shits in occupational structure. This might mean that, for instance, upward mobility in absolute terms into an higher class might not be associated with advantageous circumstances as it used to be. In turn, individuals' self-reported health might not accurately reflect a totality of health-related changes which are potentially going on in a human body.

\section{References}

Alesina, Alberto, Stefanie Stantcheva, and Edoardo Teso. 2018. "Intergenerational Mobility and Preferences for Redistribution." American Economic Review 108(2):521-54: doi:10.1257/aer.20162015.

Bartley, Mel, and Ian Plewis. 1997. "Does Health-Selective Mobility Account for Socioeconomic Differences in Health? Evidence from England and Wales, 1971 to 1991." Journal of Health and Social Behavior 38(4):376-86: doi: $10.2307 / 2955432$.

Beham, Barbara, Sonja Drobnič, Patrick Präg, Andreas Baierl, and Janin Eckner. 2019. "Part-Time Work and Gender Inequality in Europe. A Comparative Analysis of Satisfaction with Work-Life Balance." European Societies 21(3):378-402: doi:10.1080/14616696.2018.1473627. 
Beham, Barbara, Patrick Präg, and Sonja Drobnič. 2012. "Who's Got the Balance? A Study of Satisfaction with the Work-Family Balance Among Part-Time Service Sector Employees in Five Western European Countries." International Journal of Human Resource Management 23(18):3725-41: doi:10.1080/09585192.2012.654808.

Breen, Richard, and Walter Müller. 2020. Education and Intergenerational Social Mobility in Europe and the United States. Stanford, CA: Stanford University Press.

Bukodi, Erzsébet, John H. Goldthorpe, Lorraine Waller, and Jouni Kuha. 2015. "The Mobility Problem in Britain. New Findings from the Analysis of Birth Cohort Data." British Journal of Sociology 66(1):93-117: doi:10.1111/1468-4446.12096.

Bukodi, Erzsébet, Marii Paskov, and Brian Nolan. 2020. "Intergenerational Class Mobility in Europe. A New Account." Social Forces 98(3):941-72: doi:10.1093/sf/soz026.

Campos-Matos, Inês, and Ichiro Kawachi. 2015. "Social Mobility and Health in European Countries. Does Welfare Regime Type Matter?" Social Science and Medicine 142:241-48: doi:10.1016/j.socscimed.2015.08.035.

Chambers, John R., Lawton K. Swan, and Martin Heesacker. 2015. "Perceptions of US Social Mobility Are Divided (and Distorted) Along Ideological Lines." Psychological Science 26(4):413-23: doi:10.1177/0956797614566657.

Cheng, Siwei, and Fangqi Wen. 2019. "Americans Overestimate the Intergenerational Persistence in Income Ranks." Proceedings of the National Academy of Sciences 116(28):13909-14: doi:10.1073/pnas.1814688116.

Chetty, Raj, David Grusky, Maximilian Hell, Nathaniel Hendren, Robert Manduca, and Jimmy Narang. 2017. "The Fading American Dream. Trends in Absolute Income Mobility Since 1940." Science 356(6336):398- 
406: doi:10.1126/science.aal4617.

Erikson, Robert. 1984. "Social Class of Men, Women, and Families." Sociology 18(4):500-514: doi:10.1177/0038038584018004003.

Erikson, Robert, and John H. Goldthorpe. 1992. The Constant Flux. A Study of Class Mobility in Industrial Societies. Oxford: Clarendon.

Erikson, Robert, and John H. Goldthorpe. 2002. "Intergenerational Inequality. A Sociological Perspective." Journal of Economic Perspectives 16(3):31-44: doi:10.1257/089533002760278695.

ESS. 2002. European Social Survey Round 1. Bergen: NSD Norwegian Center for Research Data. doi:10.21338/NSD-ESS1-2002.

ESS. 2004. European Social Survey Round 2. Bergen: NSD Norwegian Center for Research Data. doi:10.21338/NSD-ESS2-2004.

ESS. 2006. European Social Survey Round 3. Bergen: NSD Norwegian Center for Research Data. doi:10.21338/NSD-ESS3-2006.

ESS. 2008. European Social Survey Round 4. Bergen: NSD Norwegian Center for Research Data. doi:10.21338/NSD-ESS4-2008.

ESS. 2010. European Social Survey Round 5. Bergen: NSD Norwegian Center for Research Data. doi:10.21338/NSD-ESS5-2010.

Ganzeboom, Harry B. G. 2013. ISCO-88 Codes for Parental Occupations in the European Social Survey Rounds 1-5. Amsterdam: VU University.

Grätz, Michael, Kieron Barclay, Øyvind N. Wiborg, Torkild H. Lyngstad, Aleksi Karhula, Jani Erola, Patrick Präg, Thomas Laidley, and Dalton Conley. 2019. "Universal Family Background Effects on Education Across and Within Societies." Stockholm Research Reports in Demography 2019(13): doi:10.17045/sthlmuni.7999148.v1.

Grol-Prokopczyk, Hanna, Emese Verdes-Tennant, Mary McEniry, and Márton Ispány. 2015. "Promises and Pitfalls of Anchoring Vignettes in Health 
Survey Research." Demography 52(5):1703-28: doi:10.1007/s13524-0150422-1.

Grossman, Michael. 1972. "On the Concept of Health Capital and the Demand for Health." Journal of Political Economy 80(2):223-55: doi:10.1086/259880.

Gugushvili, Alexi, Ewa Jarosz, and Martin McKee. 2019. "Compared with Whom? Reference Groups in Socio-Economic Comparisons and SelfReported Health in 34 Countries." International Journal of Epidemiology 48(5):1710-20: doi:10.1093/ije/dyz122.

Gugushvili, Alexi, and Caspar Kaiser. 2020. "Equality of Opportunity Is Linked to Lower Mortality in Europe." Journal of Epidemiology and Community Health 74(2):151: doi:10.1136/jech-2019-212540.

Gugushvili, Alexi, Martin McKee, Michael Murphy, Aytalina Azarova, Darja Irdam, Katarzyna Doniec, and Lawrence King. 2019. "Intergenerational Mobility in Relative Educational Attainment and Health-Related Behaviors." Social Indicators Research 141:413-41: doi:10.1007/s11205017-1834-7.

Gugushvili, Alexi, Aaron Reeves, and Ewa Jarosz. 2020. "How Do Perceived Changes in Inequality Affect Health?" Health and Place 63:102276: doi:https://doi.org/10.1016/j.healthplace.2019.102276.

Gugushvili, Alexi, Yizhang Zhao, and Erzsébet Bukodi. 2019. "'Falling from Grace' and 'Rising from Rags.' Intergenerational Educational Mobility and Depressive Symptoms." Social Science and Medicine 222:294-304: doi:10.1016/j.socscimed.2018.12.027.

Hadjar, Andreas, and Robin Samuel. 2015. "Does Upward Social Mobility Increase Life Satisfaction? A Longitudinal Analysis Using British and Swiss Panel Data." Research in Social Stratification and Mobility 39:48-58: doi:10.1016/j.rssm.2014.12.002. 
Harbord, Roger M., and Julian P. T. Higgins. 2008. "Meta-Regression in Stata." Stata Journal 8(4):493-519: doi:10.1177/1536867X0800800403.

Huijts, Tim, Per Stornes, Terje A. Eikemo, Clare Bambra, and The HiNews Consortium. 2017. "The Social and Behavioral Determinants of Health in Europe." European Journal of Public Health 27(Supplement 1):55-62: doi:10.1093/eurpub/ckw231.

Idler, Ellen L., Shawna V. Hudson, and Howard Leventhal. 1999. "The Meanings of Self-Ratings of Health. A Qualitative and Quantitative Approach." Research on Aging 21(3):458-76: doi:10.1177/0164027599213006.

Kaiser, Caspar. 2019. "DRM. Diagonal Reference Model for Stata." Open Science Framework, doi:10.17605/OSF.IO/KFDP6.

Kaiser, Caspar, and Nhat An Trinh. 2019. "Positional, Mobility, and Reference Effects. How Does Social Class Affect Life Satisfaction in Europe?" Socarxiv, doi:10.31235/osf.io/4adhe.

Kraus, Michael W., and Jacinth J. X. Tan. 2015. "Americans Overestimate Social Class Mobility." Journal of Experimental Social Psychology 58:10111: doi:10.1016/j.jesp.2015.01.005.

Lorem, Geir, Sarah Cook, David A. Leon, Nina Emaus, and Henrik Schirmer. 2020. "Self-Reported Health as a Predictor of Mortality. A Cohort Study of Its Relation to Other Health Measurements and Observation Time." Scientific Reports 10(4886):1-9: doi:10.1038/s41598-020-61603-0.

Mackenbach, Johan P. 2019. Health Inequalities. Persistence and Change in European Welfare States. Oxford: Oxford University Press. doi:10.1093/oso/9780198831419.001.0001.

Mackenbach, Johan P., Marina Karanikolos, and Martin McKee. 2013. "The Unequal Health of Europeans. Successes and Failures of Policies." Lancet 381(9872):1125-34: doi:10.1016/S0140-6736(12)62082-0.

Marmot, Michael. 2005. "Social Determinants of Health Inequalities." Lancet 
365(9464):1099-1104: doi:10.1016/S0140-6736(05)71146-6.

McFadden, Emily, Robert Luben, Sheila Bingham, Nicholas Wareham, AnnLouise Kinmonth, and Kay-Tee Khaw. 2009. "Does the Association Between Self-Rated Health and Mortality Vary by Social Class?" Social Science and Medicine 68(2):275-80: doi:10.1016/j.socscimed.2008.10.012.

Mills, Melinda, and Patrick Präg. 2016. "Methodological Advances in Cross-National Research. Multilevel Challenges and Solutions." European Sociological Review 32(1):1-2: doi:10.1093/esr/jcw009.

Narayan, Ambar, Roy van der Weide, Alexandru Cojocaru, Christoph Lakner, Silvia Redaelli, Daniel Gerszon Mahler, Rakesh Gupta N. Ramasubbaiah, and Stefan Thewissen. 2018. Fair Progress? Economic Mobility Across Generations Around the World. Washington, DC: World Bank. doi:10.1596/978-1-4648-1210-1.

Newman, Katherine S. 1999. Falling from Grace. Downward Mobility in the Age of Affluence. 2nd ed. Berkeley, CA: University of California Press.

Paskov, Marii, Patrick Präg, and Lindsay Richards. 2020. "Does Downward Social Mobility Make People More Hostile Towards Immigrants?" Research in Social Stratification and Mobility, doi:10.31235/osf.io/yxe7u.

Präg, Patrick. 2019. "Visualizing Individual Outcomes of Social Mobility Using Heatmaps." Socius 5:1-2: doi:10.1177/2378023119855486.

Präg, Patrick, and Alexi Gugushvili. 2020. "Replication Materials to: Intergenerational Social Mobility and Self-Rated Health in Europe." Open Science Framework, doi:10.17605/OSF.IO/RQ7SN.

Präg, Patrick, Melinda Mills, and Rafael Wittek. 2014. "Income and Income Inequality as Social Determinants of Health. Do Social Comparisons Play a Role?" European Sociological Review 30(2):218-29: doi:10.1093/esr/jct035.

Präg, Patrick, and S. V. Subramanian. 2017. "Educational Inequalities in Self- 
Rated Health Across US States and European Countries." International Journal of Public Health 62(6):709-16: doi:10.1007/s00038-017-0981-6.

Präg, Patrick, Rafael Wittek, and Melinda Mills. 2017. "The Educational Gradient in Self-Rated Health in Europe. Does the Doctor-Patient Relationship Make a Difference?" Acta Sociologica 60(4):325-41: doi:10.1177/0001699316670715.

Rose, David, and Eric Harrison. 2010. Social Class in Europe. An Introduction to the European Socio-Economic Classification. London: Routledge. doi:10.4324/9780415534239.

Schuck, Bettina, and Nadia Steiber. 2018. "Does Intergenerational Educational Mobility Shape the Wellbeing of Young Europeans? Evidence from the European Social Survey." Social Indicators Research 139(3):1237-55: doi:10.1007/s11205-017-1753-7.

Sorokin, Pitrim A. 1927. Social Mobility. New York: Harper \& Row.

Steiber, Nadia. 2019. "Intergenerational Educational Mobility and Health Satisfaction Across the Life Course. Does the Long Arm of Childhood Conditions Only Become Visible Later in Life?" Social Science and Medicine 242:112603: doi:10.1016/j.socscimed.2019.112603.

Subramanian, SV, Kelvyn Jones, Afamia Kaddour, and Nancy Krieger. 2009. "Revisiting Robinson. The Perils of Individualistic and Ecologic Fallacy." International Journal of Epidemiology 38(2):342-60: doi:10.1093/ije/dyn359.

Swift, Adam. 2004. "Would Perfect Mobility Be Perfect?" European Sociological Review 20(1):1-11: doi:10.1093/esr/20.1.1.

Vable, Anusha M., Paola Gilsanz, and Ichiro Kawachi. 2019. "Is It Possible to Overcome the 'Long Arm' of Childhood Socioeconomic Disadvantage Through Upward Socioeconomic Mobility?" Journal of Public Health 41(3):566-674: doi:10.1093/pubmed/fdz018. 
Van der Waal, Jeroen, Stijn Daenekindt, and Willem de Koster. 2017. "Statistical Challenges in Modeling the Health Consequences of Social Mobility. The Need for Diagonal Reference Models." International Journal of Public Health 62(9):1029-37: doi:10.1007/s00038-017-1018-x.

Venkataramani, Atheendar, Sebastian Daza, and Ezekiel Emanuel. 2020. "Association of Social Mobility with the Income-Related Longevity Gap in the United States. A Cross-Sectional, County-Level Study." JAMA Internal Medicine 180(3):429-36: doi:10.1001/jamainternmed.2019.6532.

Venkataramani, Atheendar S., Rachel Brigell, Rourke O'Brien, Paula Chatterjee, Ichiro Kawachi, and Alexander C. Tsai. 2016. "Economic Opportunity, Health Behaviors, and Health Outcomes in the Usa. A Population-Based Cross-Sectional Study." Lancet Public Health 1(1):e18-e25: doi:10.1016/S2468-2667(16)30005-6.

World Bank. 2020. World Development Indicators. Washington, DC: International Bank for Reconstruction and Development.

Yaish, Meir, and Robert Andersen. 2012. "Social Mobility in Twenty Modern Societies. The Role of Economic and Political Context." Social Science Research 41(3):527-38: doi:10.1016/j.ssresearch.2011.12.001. 
Supplement 
Table A1: Sample size by country and survey round, $\mathrm{N}=159,591$

\begin{tabular}{lcccccc}
\hline & & & & & & \\
& 2002 & 2004 & 2006 & 2008 & 2010 & Total \\
\hline Austria & 1,517 & 1,389 & 1,479 & 1,391 & 0 & 5,776 \\
Belgium & 1,172 & 1,165 & 1,237 & 1,182 & 1,160 & 5,916 \\
Bulgaria & 0 & 0 & 1,000 & 1,809 & 2,037 & 4,846 \\
Cyprus & 0 & 0 & 661 & 772 & 703 & 2,136 \\
Czech Republic & 1,087 & 2,022 & 0 & 1,468 & 1,694 & 6,271 \\
Denmark & 1,131 & 1,141 & 1,217 & 1,172 & 1,213 & 5,874 \\
Estonia & 0 & 1,402 & 630 & 1,140 & 1,291 & 4,463 \\
Finland & 1,417 & 1,498 & 1,410 & 1,637 & 1,379 & 7,341 \\
France & 1,031 & 1,311 & 1,469 & 1,515 & 1,300 & 6,626 \\
Germany & 2,068 & 1,972 & 1,945 & 1,958 & 2,170 & 10,113 \\
Greece & 1,594 & 1,645 & 0 & 1,356 & 1,727 & 6,322 \\
Hungary & 1,027 & 1,072 & 1,015 & 1,063 & 1,138 & 5,315 \\
Ireland & 1,229 & 1,482 & 1,031 & 1,249 & 1,543 & 6,534 \\
Italy & 582 & 818 & 0 & 0 & 0 & 1,400 \\
Latvia & 0 & 0 & 1,068 & 1,437 & 0 & 2,505 \\
Lithuania & 0 & 0 & 0 & 1,242 & 1,157 & 2,399 \\
Luxembourg & 892 & 1,070 & 0 & 0 & 0 & 1,962 \\
Netherlands & 1,653 & 1,345 & 1,390 & 1,310 & 1,393 & 7,091 \\
Norway & 1,336 & 1,331 & 1,289 & 1,162 & 1,162 & 6,280 \\
Poland & 1,358 & 1,094 & 1,110 & 1,059 & 1,151 & 5,772 \\
Portugal & 1,018 & 1,285 & 1,591 & 1,573 & 1,570 & 7,037 \\
Romania & 0 & 0 & 1,125 & 940 & 0 & 2,065 \\
Russia & 0 & 0 & 1,597 & 1,647 & 1,733 & 4,977 \\
Slovak Republic & 0 & 871 & 1,098 & 1,375 & 1,430 & 4,774 \\
Slovenia & 777 & 0 & 777 & 556 & 746 & 2,856 \\
Spain & 1,035 & 827 & 1,197 & 1,623 & 1,247 & 5,929 \\
Sweden & 1,493 & 1,443 & 1,297 & 1,369 & 1,144 & 6,746 \\
Switzerland & 1,278 & 1,637 & 1,435 & 1,323 & 1,084 & 6,757 \\
Ukraine & 0 & 1,443 & 1,393 & 1,272 & 1,305 & 5,413 \\
United Kingdom & 1,543 & 1,328 & 1,737 & 1,738 & 1,749 & 8,095 \\
Total & 26,238 & 30,591 & 31,198 & 37,338 & 34,226 & 159,591 \\
\hline Soure: ESs & $0 w 002-10$, & & & &
\end{tabular}

Source: ESS 2002-10, own calculations. 
Table A2: Descriptive statistics, $\mathrm{N}=159,591$

\begin{tabular}{|c|c|c|c|c|}
\hline & Prop./Mean & $S D$ & Min. & Max. \\
\hline Poor self-rated health & 0.10 & & 0 & 1 \\
\hline \multicolumn{5}{|l|}{ Respondent social class: } \\
\hline Salariat & 0.29 & & 0 & 1 \\
\hline Intermediate classes & 0.23 & & 0 & 1 \\
\hline Working class & 0.48 & & 0 & 1 \\
\hline \multicolumn{5}{|l|}{ Parental social class: } \\
\hline Salariat & 0.30 & & 0 & 1 \\
\hline Intermediate classes & 0.23 & & 0 & 1 \\
\hline Working class & 0.47 & & 0 & 1 \\
\hline \multicolumn{5}{|l|}{ Mobility: } \\
\hline Downwardly mobile & 0.26 & & 0 & 1 \\
\hline Immobile & 0.50 & & 0 & 1 \\
\hline Upwardly mobile & 0.24 & & 0 & 1 \\
\hline Age & 53.28 & 14.72 & 30 & 86 \\
\hline Female sex & 0.53 & & 0 & 1 \\
\hline $\mathrm{N}$ & 159,591 & & & \\
\hline
\end{tabular}

Source: ESS 2002-10, own calculations. 
Table A3: Values of country-level variables, $\mathrm{N}=30$

\begin{tabular}{|c|c|c|c|c|c|c|}
\hline & $\begin{array}{l}\text { Ratio } \\
\text { up- } \\
\text { ward/d }\end{array}$ & $\begin{array}{l}\text { 'Unidiff' } \\
\text { param- } \\
\text { weitweard }\end{array}$ & $\begin{array}{l}\% \\
\text { down- } \\
\text { wardly } \\
\text { mobile }\end{array}$ & $\begin{array}{l}\% \text { up- } \\
\text { wardly } \\
\text { mobile }\end{array}$ & $\begin{array}{l}\text { Global } \\
\text { log } \\
\text { odds } \\
\text { ratios }\end{array}$ & $\begin{array}{l}\text { GDP } \\
\text { per } \\
\text { capita }\end{array}$ \\
\hline Austria & 1.51 & 0.76 & 26 & 39 & -0.26 & 50,557 \\
\hline Belgium & 1.20 & 0.61 & 31 & 37 & -0.21 & 46,615 \\
\hline Bulgaria & 0.84 & 0.84 & 37 & 31 & 2.52 & 15,118 \\
\hline Cyprus & 1.32 & 0.81 & 28 & 36 & 0.48 & 37,734 \\
\hline Czech Republic & 0.87 & -0.31 & 38 & 33 & -0.26 & 31,154 \\
\hline Denmark & 0.97 & -0.17 & 34 & 33 & -0.08 & 51,368 \\
\hline Estonia & 0.59 & -1.83 & 47 & 27 & -0.34 & 25,965 \\
\hline Finland & 1.07 & -0.31 & 34 & 36 & -0.87 & 45,173 \\
\hline France & 1.07 & -0.50 & 35 & 37 & -1.14 & 41,969 \\
\hline Germany & 1.37 & 0.65 & 29 & 40 & 1.09 & 45,101 \\
\hline Greece & 0.99 & 0.42 & 29 & 29 & -0.61 & 35,214 \\
\hline Hungary & 0.79 & 1.25 & 37 & 29 & 2.04 & 24,196 \\
\hline Ireland & 1.33 & 0.10 & 28 & 37 & -0.72 & 55,027 \\
\hline Italy & 1.28 & 0.27 & 27 & 35 & 0.07 & 44,183 \\
\hline Latvia & 0.47 & -1.85 & 50 & 23 & -0.83 & 20,512 \\
\hline Lithuania & 0.95 & -0.94 & 37 & 35 & -0.22 & 21,934 \\
\hline Luxembourg & 1.92 & 0.89 & 24 & 45 & 1.12 & 106,345 \\
\hline Netherlands & 1.92 & 0.27 & 25 & 47 & -0.58 & 50,829 \\
\hline Norway & 0.96 & -0.63 & 36 & 34 & -1.66 & 60,419 \\
\hline Poland & 0.75 & 1.72 & 38 & 28 & 1.17 & 20,284 \\
\hline Portugal & 1.35 & 2.14 & 27 & 37 & 2.05 & 31,413 \\
\hline Romania & 1.06 & -0.76 & 34 & 36 & -0.08 & 17,984 \\
\hline Russia & 0.69 & -1.42 & 42 & 29 & -0.13 & 21,133 \\
\hline Slovak Republic & 1.01 & -0.65 & 36 & 36 & -0.45 & 22,197 \\
\hline Slovenia & 1.02 & -0.51 & 35 & 35 & -0.52 & 32,161 \\
\hline Spain & 1.37 & 1.19 & 28 & 38 & 1.00 & 37,927 \\
\hline Sweden & 1.04 & -0.46 & 35 & 36 & -0.66 & 46,412 \\
\hline Switzerland & 1.61 & 0.56 & 25 & 40 & -0.32 & 62,040 \\
\hline Ukraine & 0.93 & -0.88 & 36 & 33 & -0.39 & 11,143 \\
\hline United Kingdom & 1.08 & -1.25 & 34 & 37 & -1.08 & 42,321 \\
\hline
\end{tabular}

Source for mobility variables: Bukodi et al. (2020), for GDP: World Bank (2020). 
Table A4: Correlations between country-level variables, $\mathrm{N}=30$

\begin{tabular}{|c|c|c|c|c|c|c|}
\hline & $\begin{array}{l}\text { Ratio } \\
\text { up- } \\
\text { ward/dor }\end{array}$ & $\begin{array}{l}\text { 'Unidiff' } \\
\text { param- } \\
\text { wettard }\end{array}$ & $\begin{array}{l}\% \\
\text { down- } \\
\text { wardly } \\
\text { mobile }\end{array}$ & $\begin{array}{l}\text { \% up- } \\
\text { wardly } \\
\text { mobile }\end{array}$ & $\begin{array}{l}\text { Global } \\
\text { log } \\
\text { odds } \\
\text { ratios }\end{array}$ & $\begin{array}{l}\text { GDP } \\
\text { per } \\
\text { capita }\end{array}$ \\
\hline $\begin{array}{l}\text { Ratio up- } \\
\text { ward/downward }\end{array}$ & 1.00 & & & & & \\
\hline $\begin{array}{l}\text { 'Unidiff' parame- } \\
\text { ter }\end{array}$ & $0.50^{* *}$ & 1.00 & & & & \\
\hline $\begin{array}{l}\% \text { downwardly } \\
\text { mobile }\end{array}$ & $-0.92^{* * *}$ & $-0.66^{* * *}$ & 1.00 & & & \\
\hline $\begin{array}{l}\% \text { upwardly mo- } \\
\text { bile }\end{array}$ & $0.93^{* * *}$ & 0.32 & $-0.81^{* * *}$ & 1.00 & & \\
\hline $\begin{array}{l}\text { Global log odds } \\
\text { ratios }\end{array}$ & 0.09 & $0.70^{* * *}$ & -0.17 & -0.03 & 1.00 & \\
\hline GDP per capita & $0.72^{* * *}$ & 0.25 & $-0.62^{* * *}$ & $0.67^{* * *}$ & -0.14 & 1.00 \\
\hline
\end{tabular}

Source for mobility variables: Bukodi et al. (2020), for GDP: World Bank (2020).

${ }^{*} p<0.05,{ }^{* *} p<0.01,{ }^{* * *} p<0.001$ 
A1

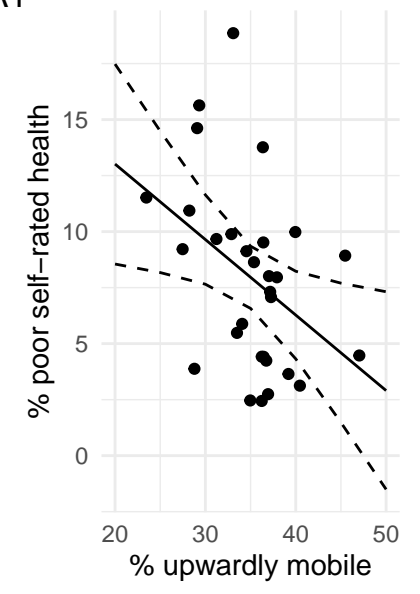

B1

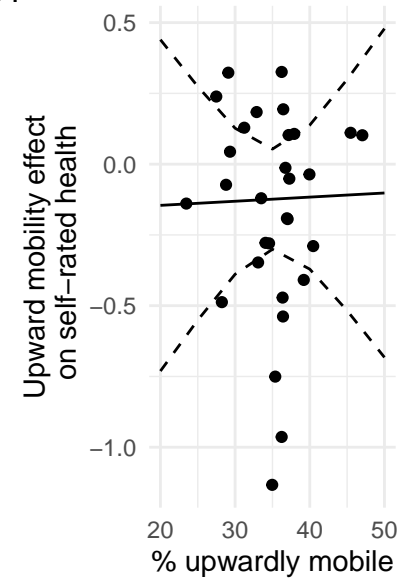

C1

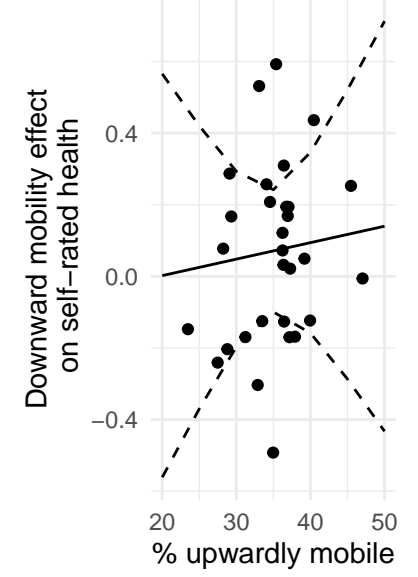

A2

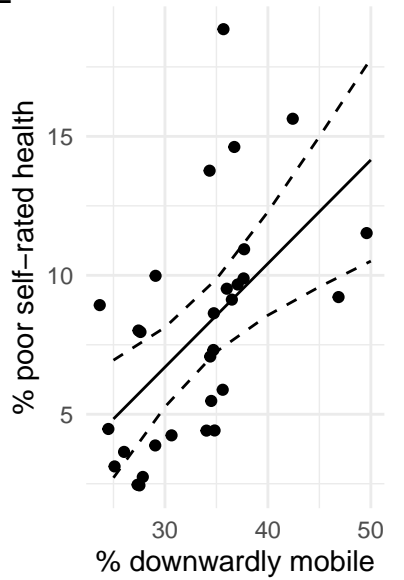

B2

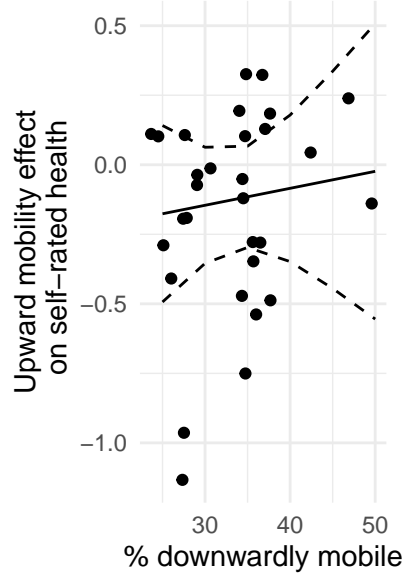

$\mathrm{C} 2$

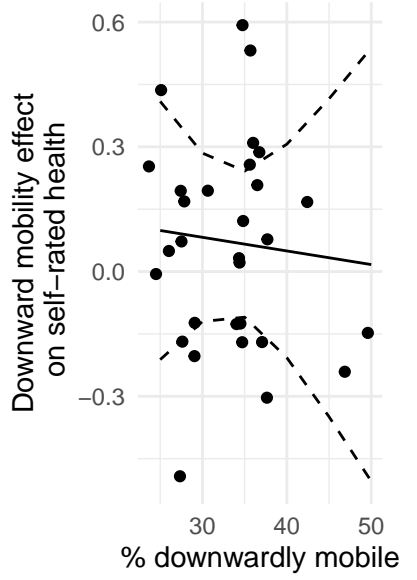

A3

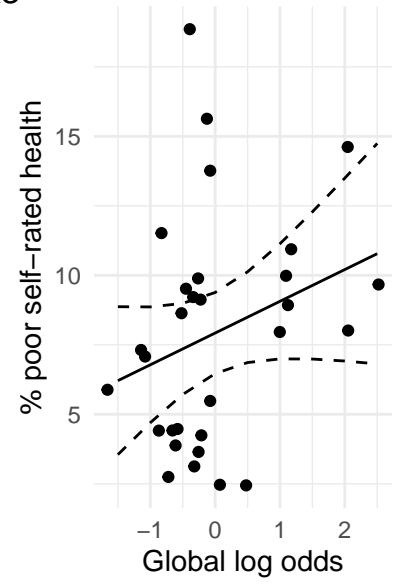

B3

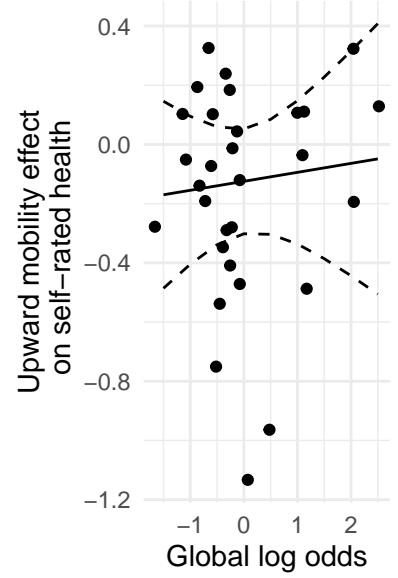

C3

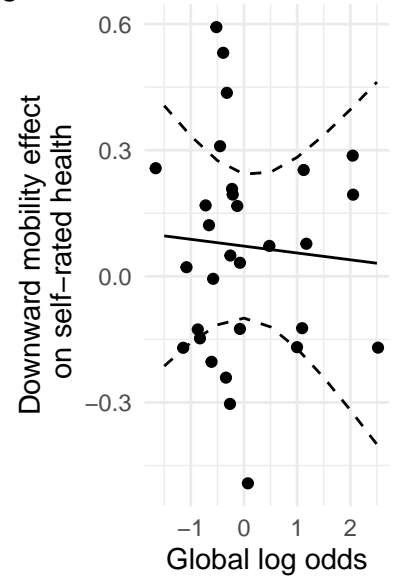

Figure A1: Top row: Indicators of absglute (Panels A1 and A2) and relative social mobility (Panel A3) plotted against predicted percentage poor health in country. Middle row: Indicators of absolute (Panels B1 and B2) and relative social mobility (Panel B3) plotted upward mobility effect on poor health in country. Bottom row: Indicators of absolute (Panels C1 and C2) and relative social mobility (Panel C3) plotted downward mobility effect on poor health in country. All analyses $\mathrm{N}=30$. 
Table A5: Percentage poor health, upward, and downward mobility effects on poor health, regressed on (1) five social mobility indicators and (2) additionally on logged GDP per capita, unstandardized coefficients from random effects meta-regression models, $\mathrm{N}=30$

\begin{tabular}{|c|c|c|c|c|c|c|}
\hline & $\begin{array}{l}\mathrm{C} \\
\text { (1) \% poor } \\
\text { health }\end{array}$ & $\begin{array}{l}(2) \% \text { poor } \\
\text { health }\end{array}$ & $\begin{array}{l}(1) \quad \mathrm{Up}- \\
\text { ward } \\
\text { mobility } \\
\text { effect }\end{array}$ & $\begin{array}{l}(2) \quad U p- \\
\text { ward } \\
\text { mobility } \\
\text { effect }\end{array}$ & $\begin{array}{l}\text { (1) Down- } \\
\text { ward } \\
\text { mobility } \\
\text { effect }\end{array}$ & $\begin{array}{l}(2) \text { Down- } \\
\text { ward } \\
\text { mobility } \\
\text { effect }\end{array}$ \\
\hline $\begin{array}{l}\text { M1: Ratio up- } \\
\text { ward/downward }\end{array}$ & & & & & & \\
\hline $\begin{array}{l}\text { Regression coeffi- } \\
\text { cient }\end{array}$ & -6.03 & 0.22 & 0.02 & -0.15 & 0.01 & 0.19 \\
\hline Standard error & 2.00 & 2.21 & 0.17 & 0.20 & 0.16 & 0.18 \\
\hline p-value & 0.01 & 0.92 & 0.89 & 0.46 & 0.94 & 0.32 \\
\hline \multicolumn{7}{|l|}{$\begin{array}{l}\text { M2: Unidiff param- } \\
\text { eter }\end{array}$} \\
\hline $\begin{array}{l}\text { Regression coeffi- } \\
\text { cient }\end{array}$ & -1.07 & -0.32 & -0.01 & -0.02 & -0.01 & -0.01 \\
\hline Standard error & 0.76 & 0.56 & 0.05 & 0.05 & 0.04 & 0.04 \\
\hline p-value & 0.17 & 0.58 & 0.87 & 0.72 & 0.84 & 0.88 \\
\hline \multicolumn{7}{|l|}{$\begin{array}{l}\text { M3: \% downwardly } \\
\text { mobile }\end{array}$} \\
\hline $\begin{array}{l}\text { Regression coeffi- } \\
\text { cient }\end{array}$ & 0.37 & 0.11 & 0.00 & 0.01 & -0.00 & -0.01 \\
\hline Standard error & 0.10 & 0.11 & 0.01 & 0.01 & 0.01 & 0.01 \\
\hline p-value & 0.00 & 0.33 & 0.72 & 0.22 & 0.79 & 0.27 \\
\hline \multicolumn{7}{|l|}{$\begin{array}{l}\text { M4: } \% \text { upwardly } \\
\text { mobile }\end{array}$} \\
\hline $\begin{array}{l}\text { Regression coeffi- } \\
\text { cient }\end{array}$ & -0.34 & 0.09 & 0.00 & -0.01 & 0.00 & 0.01 \\
\hline Standard error & 0.14 & 0.14 & 0.01 & 0.01 & 0.01 & 0.01 \\
\hline p-value & 0.03 & 0.55 & 0.78 & 0.58 & 0.85 & 0.27 \\
\hline \multicolumn{7}{|l|}{$\begin{array}{l}\text { M5: Global } \quad \log \\
\text { odds }\end{array}$} \\
\hline $\begin{array}{l}\text { Regression coeffi- } \\
\text { cient }\end{array}$ & 1.14 & 0.48 & 0.03 & 0.05 & -0.02 & -0.04 \\
\hline Standard error & 0.75 & 0.55 & 0.05 & 0.05 & 0.04 & 0.04 \\
\hline p-value & 0.14 & 0.40 & 0.57 & 0.35 & 0.65 & 0.31 \\
\hline
\end{tabular}


Table A6: Poor self-rated health regressed on social class and social mobility, stratified by participant sex, diagonal reference model, log odds coefficients ( $95 \%$ confidence intervals based on cluster-robust standard errors in parentheses)

\begin{tabular}{|c|c|c|c|c|}
\hline & (1) Men & (1) Women & (2) Men & (2) Women \\
\hline \multicolumn{5}{|l|}{ Immobiles } \\
\hline Salariat & $\begin{array}{c}-0.43^{* * *} \\
{[-0.50,-0.36]}\end{array}$ & $\begin{array}{c}-0.40^{* * *} \\
{[-0.47,-0.32]}\end{array}$ & $\begin{array}{c}-0.42^{* * *} \\
{[-0.50,-0.35]}\end{array}$ & $\begin{array}{c}-0.40^{* * *} \\
{[-0.50,-0.30]}\end{array}$ \\
\hline Intermediate & $\begin{array}{c}-0.07 \\
{[-0.17,0.04]}\end{array}$ & $\begin{array}{c}-0.07 \\
{[-0.15,0.00]}\end{array}$ & $\begin{array}{c}-0.05 \\
{[-0.17,0.07]}\end{array}$ & $\begin{array}{c}-0.05 \\
{[-0.18,0.07]}\end{array}$ \\
\hline Working & $\begin{array}{c}0.49^{* * *} \\
{[0.42,0.57]}\end{array}$ & $\begin{array}{c}0.47^{* * *} \\
{[0.40,0.53]}\end{array}$ & $\begin{array}{c}0.47^{* * *} \\
{[0.39,0.56]}\end{array}$ & $\begin{array}{c}0.46^{* * *} \\
{[0.38,0.54]}\end{array}$ \\
\hline \multicolumn{5}{|l|}{$\begin{array}{l}\text { Weight parame- } \\
\text { ter }\end{array}$} \\
\hline Origin weight & $\begin{array}{c}0.26 \\
{[0.19,0.32]}\end{array}$ & $\begin{array}{c}0.23 \\
{[0.17,0.29]}\end{array}$ & $\begin{array}{c}0.34 \\
{[0.13,0.54]}\end{array}$ & $\begin{array}{c}0.31 \\
{[0.04,0.57]}\end{array}$ \\
\hline \multicolumn{5}{|l|}{ Covariates } \\
\hline Age (centered) & $\begin{array}{c}0.05^{* * *} \\
{[0.04,0.06]}\end{array}$ & $\begin{array}{c}0.06^{* * *} \\
{[0.05,0.06]}\end{array}$ & $\begin{array}{c}0.05^{* * *} \\
{[0.04,0.06]}\end{array}$ & $\begin{array}{c}0.06^{* * *} \\
{[0.05,0.06]}\end{array}$ \\
\hline \multicolumn{5}{|l|}{$\begin{array}{l}\text { Mobility parame- } \\
\text { ters (ref. stable) }\end{array}$} \\
\hline \multirow[t]{2}{*}{$\begin{array}{l}\text { Downwardly mo- } \\
\text { bile }\end{array}$} & & & 0.01 & 0.03 \\
\hline & & & {$[-0.11,0.13]$} & {$[-0.11,0.17]$} \\
\hline Upwardly mobile & & & $\begin{array}{c}-0.12 \\
{[-0.30,0.06]}\end{array}$ & $\begin{array}{c}-0.08 \\
{[-0.28,0.13]}\end{array}$ \\
\hline Constant & $\begin{array}{c}-3.29^{* * *} \\
{[-3.38,-3.20]}\end{array}$ & $\begin{array}{c}-3.13^{* * *} \\
{[-3.23,-3.02]}\end{array}$ & $\begin{array}{c}-3.26^{* * *} \\
{[-3.34,-3.18]}\end{array}$ & $\begin{array}{c}-3.11^{* * *} \\
{[-3.24,-2.99]}\end{array}$ \\
\hline $\begin{array}{l}\text { Country dum- } \\
\text { mies included }\end{array}$ & Yes & Yes & Yes & Yes \\
\hline $\begin{array}{lr}\text { Survey } & \text { round } \\
\text { dummies } & \text { in- } \\
\text { cluded } & \end{array}$ & Yes & Yes & Yes & Yes \\
\hline Observations & 74,938 & 84,653 & 74,938 & 84,653 \\
\hline $\mathrm{AIC}$ & 38930.3 & 50530.6 & 38930.6 & 50533.4 \\
\hline BIC & 39004.1 & 50605.4 & 39022.9 & 50626.9 \\
\hline
\end{tabular}

$* \mathrm{p}<.05,{ }^{* *} \mathrm{p}<.01,{ }^{* * *} \mathrm{p}<.001$.

Destination parameters (which equal $-1 *$ origin parameters) and destination weight (which equals 1 - origin weight) not displayed. 
Table A7: Poor self-rated health regressed on social class and social mobility, sample restricted to participants age 30 to 60 years, diagonal reference model, log odds coefficients (95\% confidence intervals based on cluster-robust standard errors in parentheses)

(1)

$(2)$

\begin{tabular}{|c|c|c|}
\hline \multicolumn{3}{|l|}{ Immobiles } \\
\hline Salariat & $\begin{array}{c}-0.40^{* * *} \\
{[-0.48,-0.32]}\end{array}$ & $\begin{array}{c}-0.40^{* * *} \\
{[-0.48,-0.32]}\end{array}$ \\
\hline \multirow{2}{*}{ Intermediate } & $-0.12^{* * *}$ & $-0.13^{* *}$ \\
\hline & {$[-0.19,-0.06]$} & {$[-0.21,-0.05]$} \\
\hline \multirow[t]{2}{*}{ Working } & $0.52^{* * *}$ & $0.53^{* * *}$ \\
\hline & {$[0.46,0.59]$} & {$[0.46,0.60]$} \\
\hline \multicolumn{3}{|l|}{ Weight parameter } \\
\hline Origin weight & $\begin{array}{c}0.17 \\
{[0.12,0.22]}\end{array}$ & $\begin{array}{c}0.30 \\
{[0.15,0.45]}\end{array}$ \\
\hline \multicolumn{3}{|l|}{ Covariates } \\
\hline Age (centered) & $\begin{array}{c}0.07^{* * *} \\
{[0.06,0.07]}\end{array}$ & $\begin{array}{c}0.07^{* * *} \\
{[0.06,0.07]}\end{array}$ \\
\hline Female (ref. male) & $\begin{array}{c}0.18^{* * *} \\
{[0.08,0.28]}\end{array}$ & $\begin{array}{c}0.18^{* * *} \\
{[0.08,0.28]}\end{array}$ \\
\hline \multicolumn{3}{|l|}{ Mobility parameters (ref. stable) } \\
\hline Downwardly mobile & & $\begin{array}{c}0.10 \\
{[-0.03,0.23]}\end{array}$ \\
\hline Upwardly mobile & & $\begin{array}{c}-0.09 \\
{[-0.21,0.03]}\end{array}$ \\
\hline Constant & $\begin{array}{c}-3.34^{* * *} \\
{[-3.44,-3.23]}\end{array}$ & $\begin{array}{c}-3.34^{* * *} \\
{[-3.46,-3.22]}\end{array}$ \\
\hline Country dummies included & Yes & Yes \\
\hline Survey round dummies included & Yes & Yes \\
\hline Observations & 108,380 & 108,380 \\
\hline AIC & 45372.9 & 45374.3 \\
\hline BIC & 45468.9 & 45489.5 \\
\hline
\end{tabular}

$* \mathrm{p}<.05,{ }^{* *} \mathrm{p}<.01,{ }^{* * *} \mathrm{p}<.001$.

Destination parameters (which equal $-1 *$ origin parameters) and destination weight (which equals 1 - origin weight) not displayed. 
Table A8: Poor self-rated health regressed on social class and social mobility, sample restricted to participants age 30 to 70 years, diagonal reference model, log odds coefficients (95\% confidence intervals based on cluster-robust standard errors in parentheses)

$(1)$

\begin{tabular}{lcc}
\hline Immobiles & & \\
Salariat & $-0.40^{* * *}$ & $-0.40^{* * *}$ \\
Intermediate & {$[-0.46,-0.33]$} & {$[-0.46,-0.33]$} \\
& $-0.10^{* *}$ & $-0.09^{*}$ \\
Working & {$[-0.16,-0.03]$} & {$[-0.16,-0.02]$} \\
& $0.49^{* * *}$ & $0.48^{* * *}$ \\
& {$[0.44,0.55]$} & {$[0.42,0.55]$} \\
\hline Weight parameter & 0.21 & \\
Origin weight & {$[0.17,0.25]$} & 0.30 \\
& & {$[0.16,0.44]$} \\
\hline Covariates & $0.06^{* * *}$ & \\
Age (centered) & {$[0.05,0.06]$} & $0.06^{* * *}$ \\
& $0.21^{* * *}$ & {$[0.05,0.06]$} \\
Female (ref. male) & {$[0.10,0.31]$} & $0.21^{* * *}$ \\
& & {$[0.10,0.31]$} \\
Mobility parameters (ref. stable) & & 0.04 \\
Downwardly mobile & & {$[-0.06,0.15]$} \\
& & -0.09 \\
Upwardly mobile & & {$[-0.19,0.00]$} \\
& $-3.41^{* * *}$ \\
Constant & $-3.42^{* * *}$ & {$[-3.50,-3.31]$} \\
Country dummies included & Yes & Yes \\
Survey round dummies included & Yes & Yes \\
\hline Observations & 135,595 & 135,595 \\
AIC & 66115.8 & 66117.0 \\
BIC & 66204.2 & 66225.0 \\
\hline
\end{tabular}

$* \mathrm{p}<.05, * * \mathrm{p}<.01,{ }^{* * *} \mathrm{p}<.001$.

Destination parameters (which equal $-1 *$ origin parameters) and destination weight (which equals 1 - origin weight) not displayed. 
Table A9: Poor self-rated health regressed on social class and social mobility, controlling for education, diagonal reference model, log odds coefficients $(95 \%$ confidence intervals based on cluster-robust standard errors in parentheses)

(1)

\begin{tabular}{|c|c|c|}
\hline Immobiles & & \\
\hline Salariat & $-0.21^{* * *}$ & $-0.21^{* * *}$ \\
\hline & {$[-0.26,-0.16]$} & {$[-0.25,-0.16]$} \\
\hline Intermediate & $-0.11^{* * *}$ & $-0.10^{* * *}$ \\
\hline & {$[-0.17,-0.05]$} & {$[-0.16,-0.05]$} \\
\hline Working & $0.32^{* * *}$ & $0.31^{* * *}$ \\
\hline & {$[0.28,0.36]$} & {$[0.27,0.35]$} \\
\hline Weight parameter & & \\
\hline Origin weight & 0.27 & 0.22 \\
\hline & {$[0.20,0.34]$} & {$[0.04,0.40]$} \\
\hline Covariates & & \\
\hline Age (centered) & $0.05^{* * *}$ & $0.05^{* * *}$ \\
\hline & {$[0.04,0.06]$} & {$[0.04,0.06]$} \\
\hline Female (ref. male) & $0.22^{* * *}$ & $0.22^{* * *}$ \\
\hline & {$[0.11,0.33]$} & {$[0.11,0.33]$} \\
\hline Education (ref. low, ISCED 0-1) & & \\
\hline Medium (ISCED 3-4) & $-0.46^{* * *}$ & $-0.46^{* * *}$ \\
\hline & {$[-0.52,-0.40]$} & {$[-0.52,-0.40]$} \\
\hline High (ISCED 5-6) & $-0.68^{* * *}$ & $-0.68^{* * *}$ \\
\hline & {$[-0.77,-0.59]$} & {$[-0.77,-0.59]$} \\
\hline Mobility parameters (ref. stable) & & \\
\hline Downwardly mobile & & -0.04 \\
\hline & & {$[-0.12,0.04]$} \\
\hline Upwardly mobile & & -0.00 \\
\hline & & {$[-0.08,0.07]$} \\
\hline Constant & $-2.92^{* * *}$ & $-2.91^{* * *}$ \\
\hline & {$[-3.03,-2.82]$} & {$[-3.02,-2.80]$} \\
\hline Country dummies included & Yes & Yes \\
\hline Survey round dummies included & Yes & Yes \\
\hline Observations & 159,032 & 159,032 \\
\hline $\mathrm{AIC}$ & 88745.0 & 88747.8 \\
\hline $\mathrm{BIC}$ & 88854.8 & 88877.5 \\
\hline
\end{tabular}

$* \mathrm{p}<.05,{ }^{* *} \mathrm{p}<.01,{ }^{* * *} \mathrm{p}<.001$.

Destination parameters (which equal $-1 *$ origin parameters) and destination weight

(which equals 1 - origin weight) not displayed. 